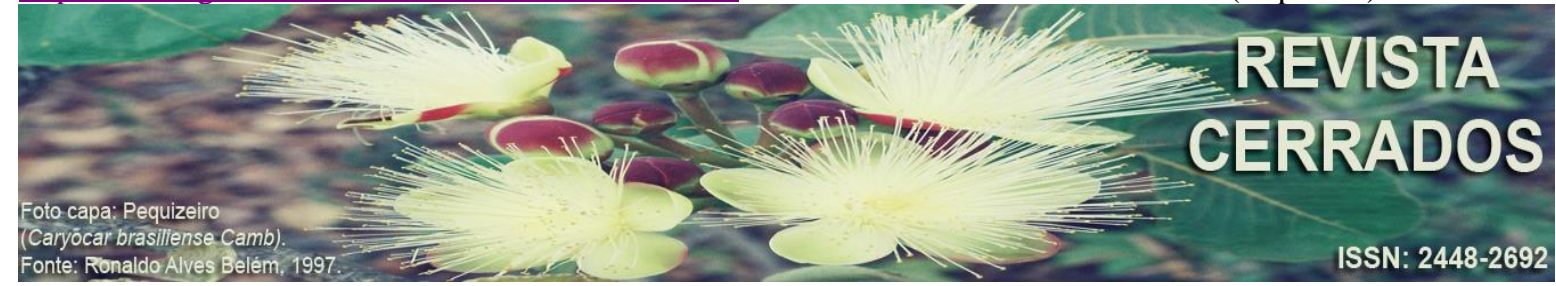

\title{
O MERCADO MUNICIPAL DE ARAGUAÍNA/TO COMO PROPULSOR DE ALIMENTOS DO CERRADO
}

\section{THE MUNICIPAL MARKET OF ARAGUAÍNA/TO AS A FOOD DRIVER IN THE CERRADO}

\section{EL MERCADO MUNICIPAL DE ARAGUAÍNA/TO COMO CONDUCTOR DE ALIMENTOS EN EL CERRADO}

\author{
Osmar Oliveira de Moura \\ Universidade Federal do Tocantins - UFT, Araguaína, Tocantins, Brasil \\ E-mail: <osmaroliveirademoura@gmail.com> \\ Ana Caroline Pereira dos Santos \\ Universidade Federal do Tocantins - UFT, Araguaína, Tocantins, Brasil \\ E-mail: <pereira.ana@uft.edu.br> \\ Silvania Reis de Araújo \\ Universidade Federal do Tocantins - UFT, Araguaína, Tocantins, Brasil \\ E-mail: <reissilvania405@gmail.com> \\ Maurício Ferreira Mendes \\ Universidade Federal do Tocantins - UFT, Araguaína, Tocantins, Brasil \\ E-mail: <mauricio.mendes@uft.edu.br>
}

\section{RESUMO}

Este estudo teve como objetivo compreender a importância do Mercado Municipal de Araguaína/TO como propulsor de alimentos do cerrado, gerando segurança alimentar e nutricional aos feirantes e aos consumidores, visto que acontece primeiramente $\mathrm{o}$ autoconsumo e posteriormente a comercialização, garantindo renda e sustento às famílias. $\mathrm{O}$ delineamento utilizado foi o estudo de caso. Foram aplicados questionários semiestruturados junto aos feirantes do Mercado Municipal, no período de setembro à novembro de 2019, além de levantamento de material bibliográfico e registro fotográfico. Os resultados mostram que houveram diversos conflitos entre feirantes e comerciantes para posterior implementação pelo poder público do Mercado Municipal de Araguaína, o que aconteceu em 1978, garantindo assim, inclusão social e renda, fortalecimento da cadeia produtiva dos frutos do cerrado, além da promoção da segurança alimentar entre feirantes e consumidores locais. Porém, esses 
MOURA, O. O.; SANTOS, A. C. P.; ARAÚJO, S. R.; MENDES, M. F.

O Mercado Municipal de Araguaína/TO como propulsor de alimentos do Cerrado

alimentos estão ameaçados com o avanço da soja e pecuária sobre o bioma cerrado, comprometendo a diversidade de produtos ofertados pelos feirantes do Mercado Municipal em Araguaína.

Palavras-chave: Espaço público. Mercado municipal. Araguaína.

\begin{abstract}
This study aimed to understand the importance of the Municipal Market of Araguaína/TO as a propellant of food in the cerrado, generating food and nutritional security for marketers and consumers, since self-consumption and then commercialization take place, guaranteeing income and sustenance for the families. The design used was the case study. Semi-structured questionnaires were applied to market vendors in the Municipal Market, from September to November 2019, in addition to a survey of bibliographic material and photographic record. The results show that there were several conflicts between marketers and traders for subsequent implementation by the public authorities of the Araguaína Municipal Market, which happened in 1978, thus guaranteeing social inclusion and income, strengthening the productive chain of cerrado fruits, in addition to promoting food security between marketers and local consumers. However, these foods are threatened by the advance of soy and livestock over the cerrado biome, compromising the diversity of products offered by market vendors in the Municipal Market in Araguaína.
\end{abstract}

Keywords: Public place. Municipal market. Araguaína.

\title{
RESUMEN
}

Este estudio tuvo como objetivo comprender la importancia del Mercado Municipal de Araguaína/TO como propulsor de alimentos en el cerrado, generando seguridad alimentaria y nutricional para comercializadores y consumidores, ya que se produce el autoconsumo y luego la comercialización, garantizando ingresos y sustento para las familias de la familia. El diseño utilizado fue el estudio de caso. Se aplicaron cuestionarios semiestructurados a vendedores de mercado en el Mercado Municipal, de septiembre a noviembre de 2019, además de una encuesta de material bibliográfico y registro fotográfico. Los resultados muestran que hubo varios conflictos entre comercializadores y comerciantes para la posterior implementación por parte de las autoridades públicas del Mercado Municipal de Araguaína, que ocurrió en 1978, garantizando así la inclusión social y los ingresos, fortaleciendo la cadena productiva de frutos cerrados, además de promover seguridad alimentaria entre comercializadores y consumidores locales. Sin embargo, estos alimentos están amenazados por el avance de la soya y el ganado sobre el bioma cerrado, lo que compromete la diversidad de productos ofrecidos por los vendedores en el Mercado Municipal de Araguaína.

Palabras-clave: Espacio público. Mercado municipal. Araguaína. 
MOURA, O. O.; SANTOS, A. C. P.; ARAÚJO, S. R.; MENDES, M. F.

O Mercado Municipal de Araguaína/TO como propulsor de alimentos do Cerrado

\section{INTRODUÇÃO}

O presente estudo teve como objetivo compreender a importância do Mercado Municipal de Araguaína/TO como propulsor de alimentos do cerrado, gerando Segurança Alimentar e Nutricional (SAN) aos feirantes e aos consumidores, visto que acontece primeiramente o autoconsumo e posteriormente a comercialização, garantindo renda e sustento às famílias dos feirantes.

O Mercado Municipal foi fundado em 1978, está localizado na área central de Araguaína, região Norte do estado do Tocantins, o município integra a Microrregião Geográfica de Araguaína ${ }^{1}$ e desde sua criação se consolidou como um espaço importante na cidade, atraindo centenas de pessoas todos os dias em busca dos frutos nativos do cerrado e de áreas de transição amazônica, como buriti (Mauritia flexuosa), pequi (Caryocar brasiliense), açaí (Euterpe oleracea), bacaba (Oenocarpus distichus) e outros, além de hortaliças, farinhas, cereais, tubérculos e também não menos procurado, os pratos típicos da região, com destaque para a panelada e o chambari. No município de Araguaína, e em cidades do entorno, frutos nativos são bastante populares e apreciados pela população.

Sendo assim, o Mercado Municipal de Araguaína é caracterizado como um centro ou feira pública, com destaque para os frutos nativos que se apresentam com propriedades vitamínicas e proteicas, além da geração de renda para as famílias dos feirantes. "O buriti e o pequi tem quantidades de betacaroteno que se transforma em vitamina $\mathrm{A}$ em nosso organismo [...]. O jatobá é rico em cálcio. Esses frutos do cerrado representam um banco de nutrientes, principalmente para a população rural", conforme estudos da Empresa Brasileira de Pesquisa Agropecuária (EMBRAPA CERRADOS, 2004, p. 3).

Porém, sabemos que o cerrado vem sendo modificado em ritmo acelerado. Em estudos de Klink e Machado (2005), os autores demonstram que essas transformações podem causar grandes danos ambientais, como fragmentação de hábitats, extinção da biodiversidade, invasão de espécies exóticas, mudança do regime de chuvas e aumento das temperaturas. Neste contexto, a conservação do bioma se torna urgente e essencial para a população.

\footnotetext{
${ }^{1}$ A Microrregião Geográfica de Araguaína (MRG) é composta por 17 municípios. Araguaína é município que mais se destaca na região, sua principal atividade é a agropecuária e o comércio, também se apresenta como polo de saúde e educação do Norte do Tocantins.
} 
MOURA, O. O.; SANTOS, A. C. P.; ARAÚJO, S. R.; MENDES, M. F.

O Mercado Municipal de Araguaína/TO como propulsor de alimentos do Cerrado

Para tanto, aplicou-se técnicas de estudos de caso no Mercado Municipal de Araguaína (Figura 1), nessa metodologia “o pesquisador não pretende intervir sobre o objeto a ser estudado, mas revelá-lo tal como ele o percebe" (GERHARDT e SILVEIRA, 2009, p. 32), e que somou-se a aplicação de questionários semiestruturados junto aos feirantes do mercado municipal, a qual teve o objetivo de diagnosticar a utilização e comercialização de frutos do cerrado, com destaque para a segurança alimentar.

Figura 1: Localização do Mercado Municipal de Araguaína/TO

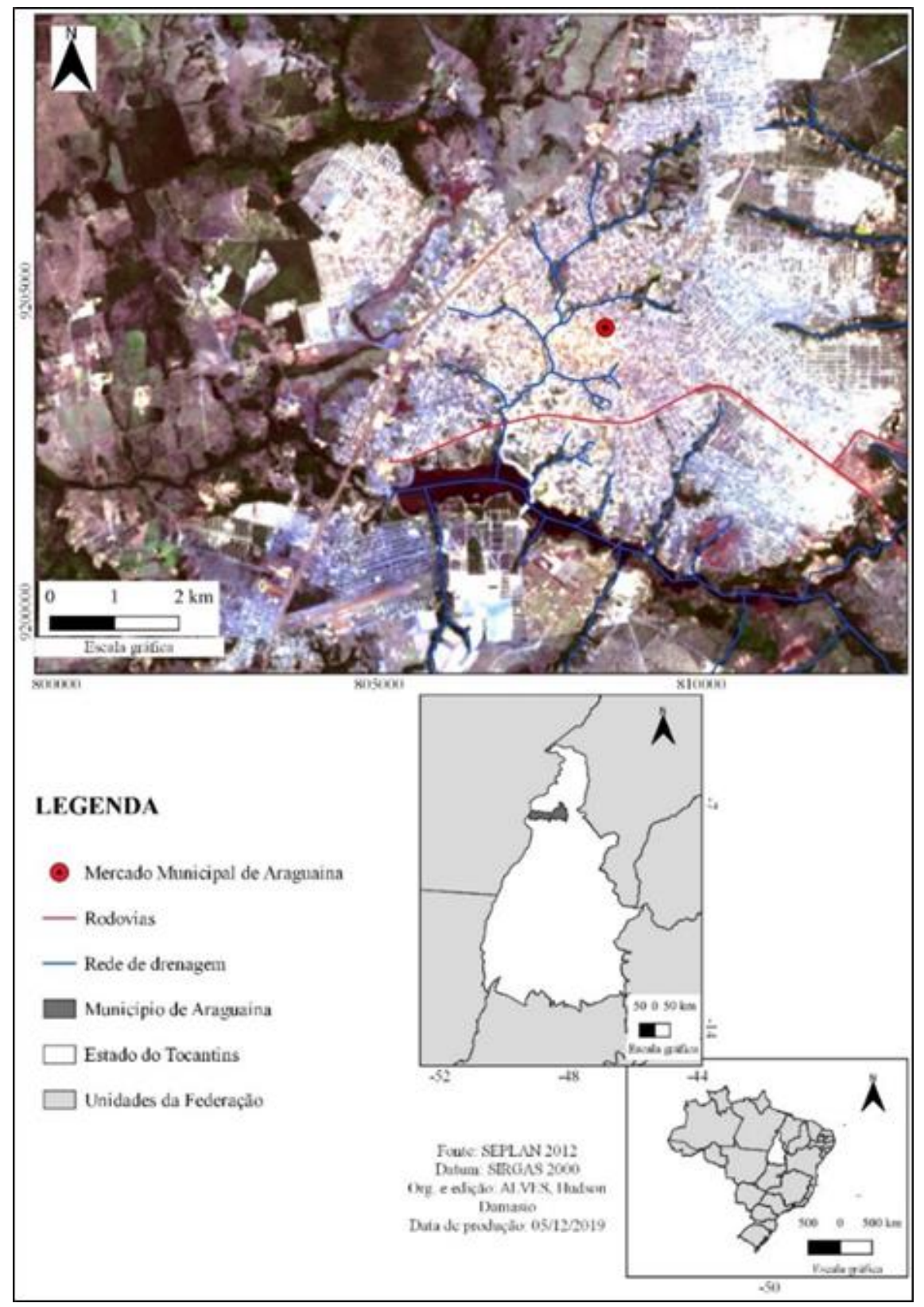

Fonte: Alves, H. D. Organização: Os autores (2020).

Revista Cerrados, Montes Claros/MG, v.18, n. 1, p. 44-65, jan./jun.-2020 
MOURA, O. O.; SANTOS, A. C. P.; ARAÚJO, S. R.; MENDES, M. F.

O Mercado Municipal de Araguaína/TO como propulsor de alimentos do Cerrado

Para responder ao objetivo proposto, estruturamos este estudo em três partes, além desta introdução, considerações finais e referências bibliográficas. Na primeira parte do texto discorremos sobre a origem do Mercado Municipal de Araguaína; na segunda discutimos o aproveitamento alimentar e comercialização dos frutos nativos dando ênfase a segurança alimentar e por fim na terceira parte abordamos as potencialidades da biodiversidade do cerrado presente no mercado, analisando o processo de degradação que o mesmo vem sofrendo em virtude do modelo de ocupação.

\section{A origem do Mercado Municipal de Araguaína}

A conquista do espaço do Mercado Municipal de Araguaína foi marcada por um longo processo de luta e persistência de muitos feirantes da cidade, no intuito de obterem o direito de comercializar seus produtos em um local apropriado e seguro. A disputa pelo território $^{2}$ era eminente e os conflitos inevitáveis, entre os feirantes, os comerciantes e do próprio poder público local, a partir sobretudo da década de 1970.

Nessa década [1970], os feirantes não tinham um espaço apropriado para comercializarem seus produtos, se posicionavam nas calçadas próximas de comércios estabelecidos na área central da cidade e por isso, tiveram que lidar com a falta de reconhecimento do seu trabalho e a rejeição por grande parte dos comerciantes e dos lojistas "legalizados". Esses comerciantes e lojistas [classe alta] como são donos de terras, lojas e têm recursos financeiros, acabam mandando e influenciando o poder público, conforme seus interesses. Por isso, foi importante a organização e união dos feirantes [classe trabalhadora] para que também tivessem o mínimo de direitos e pressionasse a prefeitura para ter um local para a comercialização. "A classe alta quer continuar sendo minoria, para repartir o que tem entre menos pessoas" (EQUIPO PLANTEL, 2016, p. 23).

Diante do exposto, os feirantes eram marginalizados por um discurso dominante que ditava que a feira era ilegal e trazia vários problemas à cidade, como o lixo acumulado e prejuízos financeiros para o comércio local, sendo desconsideradas as características próprias

\footnotetext{
${ }^{2}$ Nesta abordagem, entende-se, a categoria de análise espacial território a partir de Raffestin (1993, p. 7-8), no qual afirma que: "O território, [...] não poderia ser nada mais que o produto dos atores sociais. São esses atores que produzem o território, partindo da realidade inicial dada, que é o espaço. Há portanto um "processo" do território, quando se manifestam todas as espécies de relações de poder [...]".
} 
MOURA, O. O.; SANTOS, A. C. P.; ARAÚJO, S. R.; MENDES, M. F.

O Mercado Municipal de Araguaína/TO como propulsor de alimentos do Cerrado

e identidades daqueles sujeitos, além da ausência do poder público para enfrentar o problema. Portanto, ainda na década de 1970, as gestões desenvolvidas na cidade não apresentavam um posicionamento claro e muito menos propositivo para resolução dos problemas da não aquisição de uma área adequada para os feirantes. A respeito desta questão, Costa $(2005$, p. 7) afirma:

O discurso higienista é uma tecla que nunca deixou de ser apertada e na pauta das discussões, a feira livre [de Araguaína] aparece como sendo a "pedra no sapato" [...]. No entanto apesar de haver todo um discurso elaborado, deixou de ouvir o outro lado da história ou seja, a visão daquelas pessoas que tinham suas vidas atreladas a feira-livre. Que de uma forma ou de outra constroem a história daquele local, e que por mais que a prefeitura a enxergasse como um símbolo anti-higiênico e que, portanto esta realidade deve ser modificada, deve-se levar em conta os modos de vida que se criaram ao longo dos anos.

Os conflitos só foram amenizados com a aquisição de um espaço e início da construção do Mercado Municipal de Araguaína no final da década de 1970, após várias reivindicações e pressão dos feirantes perante o poder público municipal. A partir de então, o mercado assume um papel estratégico na cidade, que é a oferta de alimentos, visto que os feirantes em um único local possibilitaria uma maior disponibilidade de produtos, portanto, os feirantes foram contemplados nesse momento.

Conforme Silva (2016, p. 30): “A cidade é constituída como espaço produtivo ampliado, pois ela, também, concentra necessidade e oportunidade fundamentais para a população, força vital para o trabalho e o consumo”. Diante desse contexto no qual a cidade é um espaço produtivo propício ao trabalho de todos, que os feirantes reivindicaram por um espaço que possibilitasse oportunidade de renda e comercialização dos seus produtos. $\mathrm{Na}$ época, os feirantes não eram visto como agentes sociais capazes de contribuir com o processo de formação da cidade e de seu crescimento econômico, ou seja, eram marginalizados.

A inauguração do Mercado Municipal de Araguaína ocorreu no ano de 1978, quando o estado do Tocantins ainda pertencia ao estado de Goiás (BEZERRA, 2016), e o município de Araguaína tinha como prefeito Joaquim Quinta. Este empreendimento, além de atender os feirantes em razão do comércio de seus produtos específicos, trouxe significado cultural e econômico imediato para a cidade de Araguaína, proporcionando um espaço cultural para a população, gerando difusão de bens e de serviços, além da oferta de emprego e de renda para diversas famílias araguainenses. Sobre as trocas culturais construídas no mercado, Bezerra (2016, p. 65) escreve: 
MOURA, O. O.; SANTOS, A. C. P.; ARAÚJO, S. R.; MENDES, M. F.

O Mercado Municipal de Araguaína/TO como propulsor de alimentos do Cerrado

Essas trocas culturais se dão a partir do contato com os diversos produtos que ali [Mercado Municipal de Araguaína] pode ser encontrado: comidas típicas, artesanatos, remédios medicinais, doces caseiros, enfim uma gama de produtos que traduz o modo de vida, a subjetividade do seu produtor, sendo o saber fazer um elemento cultural imaterial peculiar do Município que em trocas culturais com outros Estados ao longo do tempo vem formando a identidade de Araguaína, sendo o Mercado Público Municipal um epicentro e irradiador desses elementos culturais em constante ebulição.

Dessa forma, percebe-se a importância que esta atividade produz na vida desses sujeitos, promovendo tanto o sustento de suas famílias como o rearranjo sócio espacial da cidade, visto que inúmeras outras lojas, casas, condomínios, supermercados foram construídos no entorno do mercado municipal. Ademais, a construção do Mercado na cidade trouxe como ponto positivo, a abertura de novas vagas de emprego, como afirma Barbosa (2010, p. 24): "Na realidade a modalidade de trabalho ali desenvolvida serve como uma forma do sistema absorver esta mão de obra não qualificada, e também se apresenta como meio de conter as tensões provocadas pelo desemprego".

Atualmente, o Mercado Municipal de Araguaína (Figuras 2 e 3) é autônomo, com gestão dos próprios feirantes em parceria com a Prefeitura Municipal. Os feirantes ocupam um espaço planejado para suas atividades econômicas, uma realidade alcançada somente pela articulação e luta em conjunto da classe trabalhadora dos feirantes. Desse modo, uma sociedade organizada pode influenciar e pautar a implementação de políticas públicas que atendam as demandas locais, impactando e melhorando a vida do cidadão (CASTRO, 2005).

Figura 2: Mercado Municipal de Araguaína, em 1983

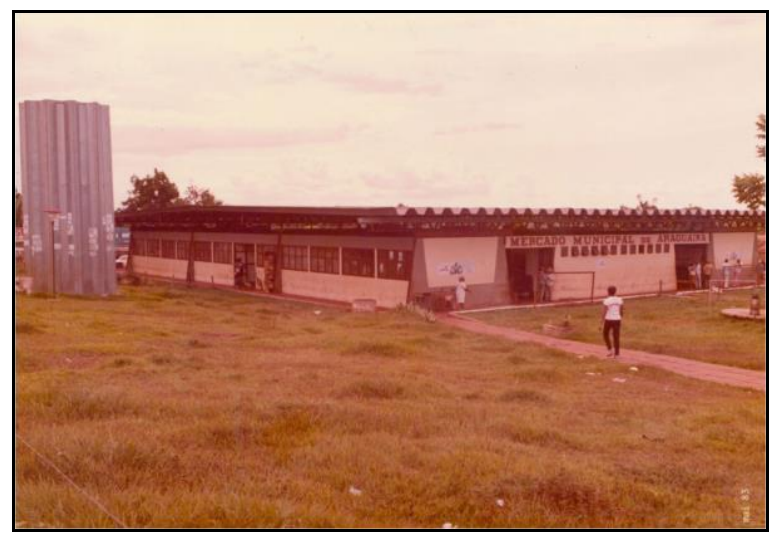

Fonte: Instituto Brasileiro Geografia e Estatística IBGE (1983).
Figura 3: Mercado Municipal de Araguaína,

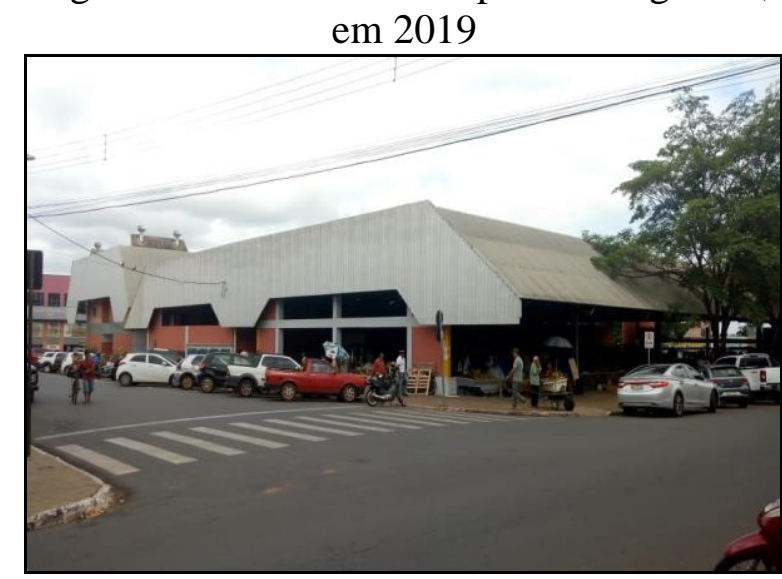

Fonte: Os autores (2019).

\footnotetext{
${ }^{3}$ Disponível em: https://biblioteca.ibge.gov.br/biblioteca-catalogo.html?id=426295\&view=detalhes. Acesso em: 01 nov. 2019.
} 
MOURA, O. O.; SANTOS, A. C. P.; ARAÚJO, S. R.; MENDES, M. F.

O Mercado Municipal de Araguaína/TO como propulsor de alimentos do Cerrado

Com 41 (quarenta e um) anos de inauguração completados em 2019, o Mercado Municipal de Araguaína conta com 209 (duzentos e nove) espaços de comercialização, incluindo bancas, boxes e salas que abrigam os produtos das diversas modalidades dos feirantes (biodiversidade do cerrado, verduras, legumes, cereais, eletrônicos, utensílios e praça de alimentação). Contribui diretamente para a renda de 230 (duzentos e trinta) famílias, sendo um total de 485 (quatrocentos e oitenta e cinco) feirantes.

Alguns dos feirantes participam de outras feiras, como as dos bairros Entroncamento e Juscelino Kubitschek, mais conhecido por "JK". No que tange a regulamentação do mercado e inserção de novos feirantes, o processo de obtenção de uma banca no estabelecimento é realizado com protocolamento de documentação na prefeitura, sendo que geralmente os espaços são repassados para outros membros da mesma família, ou seja, as bancas são passadas de geração em geração, mas também há espaços para novos feirantes.

O Mercado Municipal constituiu-se como um centro propulsor dos produtos oriundos do cerrado, uma vez que são comercializadas várias espécies de frutos, plantas medicinais, comidas típicas e resinas oriundos do cerrado e em áreas de transição amazônica. Esses produtos são bastante apreciados e consumidos pela população local, o que contribui de forma positiva com a economia e proporciona mais qualidade de vida para a população.

\section{Segurança alimentar e nutricional e comercialização no mercado municipal}

Os diversos alimentos do cerrado e das áreas de transição amazônica comercializados no Mercado Municipal de Araguaína promovem a segurança alimentar e nutricional (SAN) dos feirantes e de seus familiares e posteriormente a geração de renda, visto que os alimentos são primeiramente consumidos pelas próprias famílias dos feirantes e em seguida direcionados para a venda. A segurança alimentar afirma o direito há uma alimentação culturalmente apropriada, aos recursos para produzir alimentos, reduzindo sua dependência de mercados capitalistas (MENDES; NEVES; MACHADO, 2019).

Conforme Zuninga; Coqueiro e Siqueira (2018), por meio da comercialização em feiras livres e mercados municipais, a população pode desfrutar de uma alimentação saudável, balanceada e segura, devido à composição de proteínas e de vitaminas presentes nos 
MOURA, O. O.; SANTOS, A. C. P.; ARAÚJO, S. R.; MENDES, M. F.

O Mercado Municipal de Araguaína/TO como propulsor de alimentos do Cerrado

alimentos do cerrado, valores nutricionais imprescindíveis à saúde alimentar humana, contribuindo diretamente na promoção da segurança alimentar e nutricional.

Segundo o Artigo $3^{\circ}$ da Lei $n^{\circ} 11.346$, de 15 de setembro de 2006:

A segurança alimentar e nutricional consiste na realização do direito de todos ao acesso regular e permanente a alimentos de qualidade, em quantidade suficiente, sem comprometer o acesso a outras necessidades essenciais, tendo como base práticas alimentares promotoras de saúde que respeitem a diversidade cultural e que sejam ambiental, cultural, econômica e socialmente sustentáveis (BRASIL, 2006, p. 4).

Entretanto, verificamos que a produção de alimentos via agricultura familiar é cada vez mais difícil, uma vez que a grande maioria de recursos financeiros se encontra no modelo econômico baseado no agronegócio, mesmo assim, os agricultores familiares produzem e contribuem para a produção e para o fortalecimento da segurança alimentar e nutricional, sendo responsável por $70 \%$ dos alimentos consumidos no país.

Portanto, percebem-se desafios enormes que perduram há várias gerações: como falta de Assistência Técnica e Extensão Rural (ATER), crédito, implementação de compras públicas por parte dos gestores, acesso aos mercados institucionais, valorização dos alimentos dos agricultores familiares pelo governo e pela sociedade em geral, entre outros, que certamente culminam em dificuldades de acesso a práticas alimentares saudáveis.

Em contrapartida, o agronegócio promove a exploração dos recursos naturais, contamina água e solos com uso intensivo de venenos, tendo como carro chefe da produção a soja, algodão e milho para exportação, além de promover a exclusão de povos e de comunidades ao acesso a terra e reprodução social (MENDES; NEVES; MACHADO, 2019).

Desse modo, a produção de commodities se fortalece, com grande aporte de dinheiro público, isenção de impostos e com apoio de grandes grupos de comunicação. Barros (2018) salienta que:

O modelo do agronegócio tem dominado a propriedade privada da terra por empresas transnacionais, mas também os recursos hídricos, as florestas e os minérios, gerando fortes contradições entre os interesses capitalistas e o povo que vive no campo. Acrescenta-se ainda o controle das sementes e mudas, colocando em risco a soberania alimentar, a biodiversidade, o meio ambiente e a agricultura camponesa e familiar. As consequências são devastadoras para a vida no campo, pois aumentam as migrações internas e o inchaço das médias e grandes cidades, especialmente nas periferias, loteamentos e bairros populares (BARROS, 2018, p. 182). 
MOURA, O. O.; SANTOS, A. C. P.; ARAÚJO, S. R.; MENDES, M. F.

O Mercado Municipal de Araguaína/TO como propulsor de alimentos do Cerrado

Temos como exemplo dessa contradição a realidade do município cerradeiro de Campos Lindos, região Nordeste do Tocantins. Campos Lindos é líder em exportação de soja no estado, com cerca de 100 mil hectares, o que corresponde a $10 \%$ da produção (HASHIZUME, 2009). Porém, toda essa produção e lucros ficam nas mãos de uma pequena parcela da população, confirmado pelo IDH-M que é baixo $(0,544)$, assumindo a penúltima posição do estado, ficando somente na frente do município de Recursolândia com 0,500 de IDH-M, conforme ranking produzido pelo IBGE (2010).

Com isso, torna-se interessante os seguintes questionamentos: a alta lucratividade de empresas internacionais e de grandes fazendeiros é sinônimo de desenvolvimento para a população local? O modelo econômico adotado atinge as necessidades da população? Desse modo, o acesso a uma alimentação saudável e de qualidade se torna mais difícil. Segundo Puhl (2006), apenas 5 (cinco) empresas dominam a produção de sementes no mundo, o que concentra poder e riqueza, diminuindo a diversidade genética e inviabilizando a promoção da segurança alimentar e nutricional.

Mas se essas formas de exploração trazem grandes prejuízos socioambientais, outras como o manejo e o aproveitamento da biodiversidade do cerrado podem contribuir diretamente para o aumento da dieta alimentar das famílias e da geração de renda, como acontece com os feirantes do Mercado Municipal de Araguaína (Figuras 4 e 5).

Figura 4: Bancas dos feirantes no Mercado

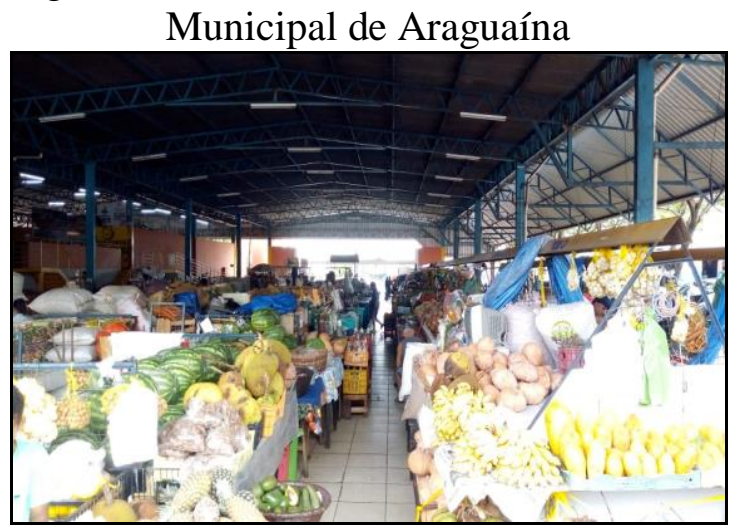

Fonte: Os autores (2019).
Figura 5: Banca com alimentos nativos do cerrado

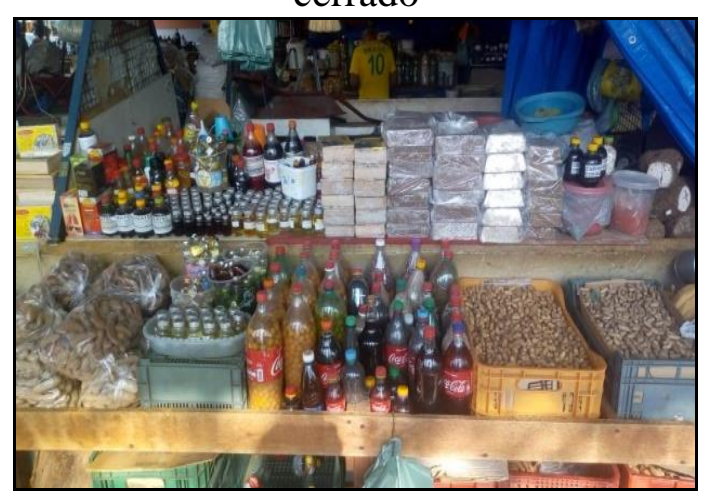

Fonte: Os autores (2019).

Desse modo, a biodiversidade do cerrado representa uma importante fonte de geração de renda para os feirantes do mercado, além disso, os frutos exercem papel estratégico no direito à segurança alimentar e nutricional, uma vez que alia os derivados do 
MOURA, O. O.; SANTOS, A. C. P.; ARAÚJO, S. R.; MENDES, M. F.

O Mercado Municipal de Araguaína/TO como propulsor de alimentos do Cerrado

cerrado juntamente com alimentos básicos dos brasileiros, como o arroz e o feijão, diversificando e melhorando a dieta alimentar do dia a dia. De acordo com Reis e Schmiele (2019, p. 2), a biodiversidade do cerrado possui componentes importantes com “[...] propriedades antioxidantes, antimicrobianas, anticarcinogênicas, antidegenerativas e retardadoras de envelhecimento".

Além do que, os frutos do cerrado e de áreas de transição amazônica no Norte do Tocantins são bastante consumidos na cidade de Araguaína e em cidades vizinhas, como em Babaçulândia, Carmolândia e Filadélfia, dentre os frutos mais apreciados e procurados pela população local segundo os feirantes do Mercado são: pequi ( $C$. brasiliense), buriti ( $M$. flexuosa), murici (Brysonima sp.), açaí (E. oleracea), babaçu (O. speciosa), bacaba ( $O$. distichus), entre outros. Esses frutos são frequentemente utilizados em pratos culinários típicos, consumidos in natura e na forma de doce, geléia e óleo.

O pequi ( $C$. brasiliense) é rico em nutrientes importantes para à saúde humana. Contém 7\% de polpa, amarela e rica em caroteno, uma substância utilizada para fins medicinais (EMBRAPA CERRADOS, 2004). O óleo extraído da polpa é utilizado na culinária regional com grande frequência, enquanto o óleo das amêndoas do fruto serve para fins medicinais, além de uso na fabricação de cosméticos (EMBRAPA CERRADOS, 2004).

O buriti (M. flexuosa) é outra espécie nativa muito apreciada pela população araguainense. Essa espécie é uma palmeira que pode chegar até 15 (quinze) metros de altura, do seu fruto, 30\% correspondem à polpa e 23\% é óleo (EMBRAPA CERRADOS, 2004). Esse fruto pode ser consumido de diversas maneiras, tanto in natura, como em sorvetes, doces e cremes, apresentando alto teor de vitamina A. Pesquisadores da Universidade Federal do Pará (UFPA) comprovaram que o óleo do buriti contém alto teor de ácido oleico, podendo ser utilizado como protetor solar natural para pele humana, devido bloquear raios solares (EMBRAPA CERRADOS, 2004).

O murici (Brysonima sp.) é outro fruto típico do cerrado e da Amazônia. De acordo com Monteiro e Pires (2016), o mesmo tem composição rica em fibras alimentares, energia, vitamina $\mathrm{C}$ e minerais como fósforo e cálcio que contribuem com uma dieta equilibrada.

O açaí (E. oleracea) é típico da Amazônia e de áreas de transição entre cerrado e floresta. Esse fruto dispõe de grande valor nutricional, tal como, elevado potencial econômico devido à alta procura pelo fruto e de seus derivados como, por exemplo, em forma de polpa, 
MOURA, O. O.; SANTOS, A. C. P.; ARAÚJO, S. R.; MENDES, M. F.

O Mercado Municipal de Araguaína/TO como propulsor de alimentos do Cerrado

sorvetes e cosméticos. Rico em vitaminas e minerais, o fruto tem alto teor em substâncias benéficas à saúde, por isso é com frequência associado a tratamentos médicos, como no caso de doenças cardiovasculares e degenerativas (OLIVEIRA; COSTA; ROCHA, 2015).

Outra espécie bastante comercializada no Mercado Municipal de Araguaína é o babaçu. Do mesocarpo do fruto é feito bolacha, pão e mingau, das cascas o subproduto originado é o carvão, além de utilizado diretamente nos alimentos na forma de farinha. Das amêndoas é fabricado o óleo, muito utilizado nas décadas de 1970 e 1980 em Araguaína e região. Na cidade de Araguaína, no parque Cimba, ainda é possível ver as ruínas de uma antiga fábrica de óleo de babaçu.

A bacaba ( $O$. distichus) também pode ser encontrada in natura e em polpa nas bancas do Mercado Municipal de Araguaína. A composição nutricional, segundo Ribeiro et al. (2017), é composta de fibras e lipídios. Este fruto assim como os outros possui sabor característico, marcante e único, tendo à apreciação da população local.

Diante do exposto, é essencial destacar neste tópico duas reflexões que estão ligadas intrinsecamente. Primeiro, o mercado municipal assume papel fundamental para o sustento das famílias dos feirantes; segundo, o mercado é um dos maiores centros difusores de produtos do cerrado do Norte do Tocantins. Portanto, cabe à reflexão sobre como ocorre o comércio no mercado, sobretudo na utilização de alimentos oriundos do cerrado, além de investigar impactos gerados, devido ao atual modelo econômico que se estabelece sobre o bioma.

Os frutos do cerrado são comercializados regionalmente, devido apresentar uma diversidade em sabor e nutrientes, consumidos in natura ou na forma de geleias, bolos, sorvetes, entre outros (RODRIGUES, 2004). Esses frutos são primeiramente consumidos pelas famílias dos feirantes e posteriormente comercializados, o que garante uma alimentação mais saudável.

Com base nos relatos dos feirantes, os produtos do cerrado ofertados no Mercado Municipal contam com boa demanda e procura pelos consumidores. Os frutos tanto in natura como processados possuem atrativo especial. Nas bancas, os consumidores locais podem encontrar, por exemplo, o óleo do pequi, do coco babaçu e buriti. Estes são os produtos mais procurados nas bancas dos feirantes. Isso em razão do conhecimento de seus benefícios à saúde. 
MOURA, O. O.; SANTOS, A. C. P.; ARAÚJO, S. R.; MENDES, M. F.

O Mercado Municipal de Araguaína/TO como propulsor de alimentos do Cerrado

As atividades comerciais exercidas no Mercado Municipal sofrem desafios, estes são ocasionados devido ao grande incentivo na região às atividades do agronegócio. Esse por sua vez dificulta as possibilidades da agricultura familiar atuar consorciadas com os produtos da biodiversidade do cerrado.

A devastação de grandes áreas de vegetação do cerrado avança principalmente na derrubada para formação de pastagens e agricultura moderna, afetando drasticamente a coleta extrativista de espécies comuns desta ecorregião. Em vista disso, essa é uma ameaça que prevê uma possível extinção de espécies singulares, prejudicando a comercialização de produtos oriundos do cerrado no Mercado Municipal de Araguaína e feiras livres operantes no estado do Tocantins e no país.

A disponibilidade desses frutos no Mercado Municipal atende a todo um contexto socioeconômico do município, o qual auxilia na renda de pessoas que de certa forma foram excluídas do mercado de trabalho por não possuírem formação adequada ou por optarem de trabalhar no Mercado, muitas vezes, as atividades de feirante são passadas de geração em geração.

Essas atividades são fundamentais para promoção da segurança alimentar e nutricional das famílias, além de agregar valor aos produtos da biodiversidade do cerrado. Soma-se a isso que os feirantes são verdadeiros guardiões do cerrado, uma vez que defendem e valorizam os produtos do bioma e cobram das autoridades a defesa do cerrado, porém o bioma cerrado vem sendo destruído na região de Araguaína, principalmente para implantação de pastagens e eucalipto, como veremos no próximo tópico.

\section{Ameaças às potencialidades da biodiversidade do cerrado tocantinense}

O cerrado é o segundo maior bioma do Brasil, considerado um dos mais ricos patrimônios do mundo em biodiversidade, com destaque para várias espécies vegetais nativas com potencial econômico e que podem ser trabalhadas pelas comunidades urbanas e rurais. De acordo com a Conservação Internacional (2005, p. 43): “O cerrado é a savana mais rica em biodiversidade do mundo, sendo espaço de refúgio natural para mais de 12.000 espécies vegetais, tal como, uma numerosa diversidade de vertebrados terrestres e aquáticos, além de invertebrados". 
MOURA, O. O.; SANTOS, A. C. P.; ARAÚJO, S. R.; MENDES, M. F.

O Mercado Municipal de Araguaína/TO como propulsor de alimentos do Cerrado

O cerrado é conhecido como berço das águas, é nesse bioma que se encontram nascentes de alguns rios que formam bacias hidrográficas importantes como a: bacia do São Francisco, Paraná e Tocantins. Todavia, a importância do cerrado vai mais além, presente em 11 (onze) estados brasileiros e no Distrito Federal (DF), a exuberância da flora e as diferentes espécies de animais representam uma das maiores biodiversidades do planeta, sendo considerado um dos "hotspots" mundiais (EMBRAPA CERRADOS, 2004).

Conforme Ganem; Drummond e Franco (2008. p. 17), "apesar de sua grande importância ecológica e de sua alta biodiversidade, o processo de ocupação do cerrado, sobretudo nos últimos cinquenta anos, vem promovendo a dilapidação acelerada do bioma". Ainda segundo os autores, a dilapidação do bioma ocorre principalmente por meio da implantação de um modelo econômico alicerçado na produção em larga escala de monoculturas por grandes propriedades.

Parte da riqueza econômica e social da biodiversidade do cerrado se encontra representada no Mercado Municipal de Araguaína. Os feirantes do mercado utilizam os frutos, plantas medicinais, resinas, tubérculos, farinhas, cascas, e outros produtos derivados do cerrado e, além disso, os comercializam. Os produtos extraídos do bioma consistem em uma fonte geradora de renda para os trabalhadores do mercado. Estes trabalhadores [feirantes] vêm no mercado à única opção de trabalho disponível, do mesmo modo, que também construíram ao longo do tempo laços de pertencimento com este lugar ${ }^{4}$.

Nesse contexto, o Mercado Municipal, se apresenta como um difusor das riquezas do cerrado, com vários produtos a disposição dos consumidores, contribuindo para manter o cerrado em pé e gerar renda, porém, o mesmo está sendo destruído a ritmo acelerado para implantação das culturas de soja, eucalipto e principalmente para as pastagens na Microrregião Geográfica de Araguaína.

Na concepção de Ab’Sáber (2003) existem formas de ocupação no domínio dos cerrados que tem contribuído para o desmatamento da sua cobertura vegetal e para a degradação dos solos. As ações antrópicas exercidas nesse bioma contribuem com a escassez da biodiversidade vegetal e extinção das espécies endêmicas. Os topos das chapadas

\footnotetext{
${ }^{4}$ Analisa-se o Mercado Municipal de Araguaína enquanto um lugar de apego, de vivência, pertencimento e familiaridade dos feirantes (TUAN, 1983).
}

Revista Cerrados, Montes Claros/MG, v.18, n. 1, p. 44-65, jan./jun.-2020 
MOURA, O. O.; SANTOS, A. C. P.; ARAÚJO, S. R.; MENDES, M. F.

O Mercado Municipal de Araguaína/TO como propulsor de alimentos do Cerrado

localizadas no Tocantins e em estados vizinhos como a Bahia e o Maranhão têm concentrado grande parte da produção do agronegócio (SOUZA, 2016).

Reflexos desse cenário de desrespeito com a biodiversidade e com os povos do cerrado são sentidos pelos feirantes do Mercado Municipal de Araguaína, conforme relatado pela feirante M. S. (outubro, 2019).

\begin{abstract}
O cerrado não existe mais [...] porque tudo que é bom vai se acabar, éramos para ter um cerrado cheio de cajuí [Anacardium humile] é fruto do cerrado agora do inverno era para termos castanha, mas não existe mais. Puçá [Mouriri pusa Gardner] é do cerrado, mangaba [Hancornia speciosa] é do cerrado, araçá [Psidium cattleianum]. [...] Então, isso tudo é fruta que eu comia que eu subia no pé para tirar [...] oiti [Licania tomentosa] é fruto do cerrado [...] é coisa de Deus que os homens destruiu [...] quem invadiu a maioria do espaço, em primeiro lugar foi os pecuaristas, depois os políticos e empresários [...]" (M.S. - Entrevista realizada em outubro de 2019).
\end{abstract}

A partir da década de 1970, se iniciou a expansão da fronteira agrícola no cerrado, esse processo conhecido como modernização da agricultura, tinha como objetivos a incorporação de novos meios de produção, como máquinas modernas, sementes híbridas e uso intenso de agrotóxicos, sobretudo, na produção de commodities para exportação. "O Estado renuncia, parcialmente, à sua posição de comando dos circuitos espaciais produtivos, e essa tarefa é assumida por grandes empresas do agronegócio. Podemos falar então de uma agricultura científica globalizada" (CASTILLO, 2007, p. 22).

Ocultados por trás desses objetivos, estavam interesses econômicos e mercadológicos gigantescos. Prova disso, é que a modernização da agricultura não só excluiu a população responsável pela produção de alimentos no Brasil, deste processo, como também, contribuiu para a intensificação da desigualdade na distribuição de terras e o aumento da pobreza e da insegurança alimentar no campo e na cidade, além da degradação dos recursos naturais (MENDES, 2017).

Nessas condições, é ilusório pensar na existência de políticas públicas capazes de melhorar as condições de renda da população e de acesso à biodiversidade de forma sustentável. Para aumento da renda dos países agrícolas, desenvolvimento e modernização, seria necessário estabelecer um sistema internacional de comércio, diferente do atual, que privilegia apenas os países desenvolvidos (MAZOYER e ROUDART, 2009).

Diante disso, pode-se indagar, que essa visão sobre o cerrado incentivou a implantação e a consolidação de uma lógica econômica hegemônica do capital, que visa à produção de commodities para exportação e a obtenção de lucros em detrimento dos recursos 
MOURA, O. O.; SANTOS, A. C. P.; ARAÚJO, S. R.; MENDES, M. F.

O Mercado Municipal de Araguaína/TO como propulsor de alimentos do Cerrado

naturais. À vista disso, questiona-se também, que esse modelo econômico traz impactos socioambientais que atingem diretamente o bioma, desconsiderando os saberes e as identidades de povos e comunidades tradicionais que habitavam esta ecorregião, sendo assim, foi um lugar "propício" para o estabelecimento do "progresso" e a acumulação de capital, sobretudo para as empresas internacionais.

Acerca das abordagens que foram construídas a respeito do cerrado ao longo do tempo, Castilho e Chaveiro (2010, p. 38) destacam que, primeiramente o bioma "[...] é identificado a partir do 'pré-conceito' e do desprezo. Por conseguinte, têm-se, também, abordagens que o tratam apenas como ambiente natural", desprovido de pessoas e saberes.

$\mathrm{Na}$ contemporaneidade, o imaginário sobre o cerrado possui em seu bojo estereótipos [“o cerrado é seco" etc.] e contradições [“as riquezas do cerrado" etc.]. Ao problematizar sobre esta questão, Chaveiro e Barreira (2010) apontam que o cerrado é aceito enquanto "marca", entretanto, esta apropriação possui contradições, pois o bioma enquanto "marca", é bem visto e usado no mercado como, por exemplo, pelo marketing ["Bolos do cerrado" "Doces do cerrado" "Sucos do cerrado" etc.]. Desse modo, o cerrado é apropriado enquanto marca por empresas, portanto, evidencia grande contradição, em vista que o mesmo modelo econômico que se apropria, também é o que destrói sua biodiversidade.

Uma das principais ameaças para o cerrado tocantinense é a criação do Matopiba ${ }^{5}$, que é a região considerada a grande fronteira agrícola nacional da atualidade e compreende o bioma cerrado dos estados do Maranhão, Tocantins, Piauí e Bahia. Lima (2019, p. 159) identifica que o "Matopiba constitui uma área de $731.734,85 \mathrm{~km}^{2}$, cerca de $35 \%$ do total da área do cerrado brasileiro".

O Estado media a criação de formas adequadas no cerrado brasileiro para a produção de commodities para mercado mundial, aumentando a instabilidade espacial em função da turbulência do mercado, exigindo contínuas readaptações das técnicas envolvidas, das empresas, das instituições nas RPAs, [Regiões Produtivas Agrícolas] aqui operacionalizada no Matopiba (LIMA, 2019, p. 150).

Desse modo, grandes empresas se instalam e avançam com sua produção sobre áreas do cerrado, a partir de políticas de incentivos fiscais e legislações que regulamentam

\footnotetext{
${ }^{5}$ O Matopiba compreende os estados do Maranhão, Tocantins, Piauí e Bahia, totalizando 143 milhões de hectares do bioma cerrado e responde por grande parte da produção brasileira de grãos e de fibras. Foi implementado pelo Decreto Presidencial n. ${ }^{\circ} 8.447$ de 06 de maio de 2015.
} 
MOURA, O. O.; SANTOS, A. C. P.; ARAÚJO, S. R.; MENDES, M. F.

O Mercado Municipal de Araguaína/TO como propulsor de alimentos do Cerrado

suas atividades, beneficiando uma pequena parcela da população, como os fazendeiros e os empresários rurais (LIMA, 2019).

As mutações que vêm acontecendo no cerrado para atender esta lógica de produção dominante, trazem no seu bojo danos ambientais e consequentemente impactos sociais que são manifestados nos diversos territórios. Klink e Machado (2005, p. 148) destacam alguns destes danos ambientais, que são a "fragmentação de hábitats, extinção da biodiversidade, invasão de espécies exóticas, erosão dos solos, poluição de aquíferos, degradação de ecossistemas, alterações nos regimes de queimadas, desequilíbrios no ciclo do carbono [...]”, além de trazer “[...] possivelmente modificações climáticas regionais".

É neste contexto espacial de conflito entre a acumulação de capital, desmatamento e desterritorialização de povos e de comunidades, que o Tocantins se destaca entre os estados cerradeiros que mais desmataram o bioma em 2018, sendo prioritariamente para formação de pastagem e o plantio de soja (DROST et al., 2019). "Em 2018, o desmatamento no Tocantins foi de 153.320 ha [hectares], ou 23\% do total desmatado no cerrado" (DROST et al, 2019, p. $1)$.

Assim, a agricultura moderna se estabelece sobre territórios, muitas vezes dizima ou expropria comunidades inteiras, aumentando ainda mais a concentração de terras. $\mathrm{O}$ agronegócio se apropria destas terras estabelecendo nelas produção em alta escala que resulta em acumulação de capital, na maior parte para empresas internacionais e consequentemente ocorre a destruição da biodiversidade do cerrado tocantinense.

Portanto, as considerações feitas neste tópico, são importantes para se perceber que, a macro cadeia produtivo-econômica instaurada em áreas de cerrado brasileiro e tocantinense não atende a uma lógica de produção sustentável, ao invés disso, se estabelece no domínio, desequilibrando e modificando todo o ecossistema, derrubando áreas inteiras de vegetação nativa, extinguindo inúmeras espécies que ainda não foram descritas pela ciência.

Em contrapartida, pode-se ressaltar a importância da conservação do cerrado para as comunidades locais, frente ao comércio de produtos extraídos deste bioma para uso e comercialização no Mercado Público Municipal de Araguaína. Essa atividade comercial é significativa para os feirantes do local, e que se sustenta ainda devido à vegetação nativa do bioma que sobrevive e pede socorro. 
MOURA, O. O.; SANTOS, A. C. P.; ARAÚJO, S. R.; MENDES, M. F.

O Mercado Municipal de Araguaína/TO como propulsor de alimentos do Cerrado

\section{CONSIDERAÇÕES FINAIS}

Os frutos do cerrado presentes no Mercado Municipal de Araguaína são fundamentais como potencial gerador de renda para diversos feirantes, pois estes incrementam as vendas com vários alimentos do cerrado, por exemplo, ervas, resinas, tubérculos, farinhas e óleos.

Além de gerar renda, esses alimentos contribuem diretamente para fortalecimento da segurança alimentar e nutricional dos feirantes e dos consumidores, uma vez que primeiramente os alimentos são consumidos pelas famílias dos feirantes e posteriormente são comercializados, além do que os frutos do bioma representam um banco de nutrientes e vitaminas, que devem ser utilizados pela população local.

O Mercado Municipal de Araguaína representa mesmo antes de sua inauguração um símbolo de resistência e luta dos feirantes [classe trabalhadora] que foram excluídos de possibilidades de trabalho formal, no entanto, construíram um espaço, criando laços de pertencimento e vínculo com o lugar. Desse modo, o Mercado Municipal consiste em um centro gerador de renda e de perpetuação de laços culturais construídos historicamente por esses feirantes.

Nesse contexto, o Mercado Municipal consiste em um dos principais centros difusores de comercialização de produtos do cerrado e de áreas de transição com a floresta amazônica do Norte do Tocantins. Os principais produtos comercializados são: o pequi ( $C$. brasiliense), buriti (M. flexuosa), murici (Brysonima sp.), açaí (E. oleracea), babaçu (O. speciosa) e bacaba (O. distichus). Esses frutos são apreciados pela população local e utilizados em pratos culinários típicos, consumidos in natura e na forma de doce, geléia e óleo.

Por fim, o cerrado e sua biodiversidade estão refém do modelo econômico de produção vigente, que se encontra implantado no bioma com recursos públicos da sociedade. Esse modelo econômico avança no Tocantins, principalmente com a criação de gado e da plantação de soja, beneficiando grandes fazendeiros e empresas internacionais e consequentemente a destruição da biodiversidade do cerrado. Com essa destruição fica cada vez mais difícil o acesso aos produtos oriundos do bioma, colocando em risco a sua oferta aos feirantes do Mercado Público Municipal de Araguaína e da população local e/ou regional. 
MOURA, O. O.; SANTOS, A. C. P.; ARAÚJO, S. R.; MENDES, M. F.

O Mercado Municipal de Araguaína/TO como propulsor de alimentos do Cerrado

\section{REFERÊNCIAS}

AB' SABER, A. N. Os domínios de natureza no Brasil: potencialidades paisagísticas. São Paulo: Ateliê Editorial, 2003.

BARBOSA, M. G. R. O Mercado Municipal de Araguaína: um Enfoque Sobre Comércio Informal. 2010. 30 f. Monografia (Graduação em Geografia) - Universidade Federal do Tocantins, Araguaína/TO, 2010.

BARROS, I. F. O agronegócio e a atuação da burguesia agrária: considerações da luta de classes no campo. Serviço Social \& Sociedade, São Paulo, n. 131, p.175-195, 2018.

BEZERRA, J. L. M. Educação Patrimonial: novas perspectivas para o ensino de História. 2016. 119 f. Dissertação (Mestrado Profissional em Ensino de História). Universidade Federal do Tocantins, Araguaína/TO, 2016.

BRASIL. Lei $\mathbf{n}^{\circ}$ 11.346, de 15 de setembro de 2006. Cria o Sistema Nacional de Segurança Alimentar e Nutricional - SISAN com vistas em assegurar o direito humano à alimentação adequada e dá outras providências. Disponível em:

http://www.planalto.gov.br/ccivil_03/_Ato2004-2006/2006/Lei/L11346.htm. Acesso em: 16 dez. 2019.

CASTILLO, R. Agronegócio e Logística em áreas de cerrado: expressão da agricultura científica globalizada. Revista da ANPEGE, João Pessoa, v. 3, n. 3, p. 21-27, 2007.

CASTILHO, D. CHAVEIRO, E. F. Por uma análise territorial do cerrado. In: PELÁ, M.; CASTILHO, D. (Orgs.). Cerrados: perspectivas e olhares. Goiânia: Editora Vieira, 2010. p.35-50.

CASTRO, I. E. Geografia política: território, escalas de ação e instituições. Rio de Janeiro: Bertrand Brasil, 2005.

CHAVEIRO, E. F.; BARREIRA, C. C. M. A. Cartografia de um pensamento de cerrado. In: PELÁ, M.; CASTILHO, D. (Orgs.). Cerrados: perspectivas e olhares. Goiânia: Editora Vieira, 2010. p. 15-33.

COSTA, L. D. Relações sociais na cidade de Araguaína: um enfoque sobre o mercado municipal (1971-2005). 2005. 32 f. Monografia (Graduação em História). Universidade Federal do Tocantins, Araguaína/TO, 2005.

CONSERVAÇÃO INTERNACIONAL. Relatório anual de atividades. 2005. Disponível em: https://www.conservation.org/docs/default-source/brasil/ci-relatorio-anual-de-atividades2005-baixa-150.pdf?sfvrsn=d657d7e8_2. Acesso em: 10 dez. 2019.

DROST, S.; KUEPPER, A. B.; PIOTROWSKI, P. M; ADVISERS, C. Tocantins: um hotspot para o desmatamento do cerrado. 2019. Disponível em: 
MOURA, O. O.; SANTOS, A. C. P.; ARAÚJO, S. R.; MENDES, M. F.

O Mercado Municipal de Araguaína/TO como propulsor de alimentos do Cerrado

https://chainreactionresearch.com/wp-content/uploads/2019/04/CRR_Tocantins-Report-

Portuguese.pdf. Acesso em: 06 out. 2019.

EMBRAPA CERRADOS. Manejo e aproveitamento de frutas nativas do cerrado.

Brasília: Embrapa Cerrados, 2004.

EQUIPO PLANTEL. O que são classes sociais? São Paulo: Boitatá, 2016.

GANEM, R. S.; DRUMMOND, J. A.; FRANCO, J. L. A. Ocupação humana e impactos ambientais no bioma cerrado: dos bandeirantes à política de biocombustíveis. In: IV Encontro Nacional da Anppas, 2008, Brasília. p. 1-20. Disponível em:

http://www.anppas.org.br/encontro4/cd/ARQUIVOS/GT5-484-211-20080518092403.pdf.

Acesso em: 06 fev. 2019.

GERHARDT, T. E.; SILVEIRA, D.; T. Métodos de pesquisa. Porto Alegre: Editora da UFRGS, 2009.

HASHIZUME, M. Município do Tocantins lidera ranking de soja e de pobreza. Disponível em: https://reporterbrasil.org.br/2009/07/municipio-do-tocantins-lidera-rankingde-soja-e-de-pobreza/. Acesso em: 21 dez. 2019.

IBGE. Instituto Brasileiro de Geografia e Estatística. Índice de Desenvolvimento Humano. 2010. Disponível em:

https://cidades.ibge.gov.br/brasil/to/pesquisa/37/30255?tipo=ranking\&localidade $1=170384$.

Acesso em: 22 dez. 2019.

KLINK, C. A.; MACHADO, R. B. A conservação do cerrado brasileiro. Revista

Megadiversidade, Belo Horizonte, v. 1, n. 1, p. 147-155, 2005.

LIMA, D. A. Terra, trabalho e acumulação: o avanço da soja na região Matopiba. 2019. $291 \mathrm{f}$ (Doutorado em Geografia) - Universidade Estadual de Campinas, Instituto de Geociências, Campinas, SP, 2019.

MAZOYER, M.; ROUDART, L. História das agriculturas no mundo do neolítico à crise contemporânea. São Paulo: Editora UNESP, 2008.

MENDES, M. F. Políticas públicas em assentamentos rurais: potencialidades e limitações do PAA e do PNAE em Mato Grosso. 2017. 234 f. Tese (Doutorado) Universidade Federal de Goiás, Instituto de Estudos Socioambientais (IESA/UFG), Programa de Pós-Graduação em Geografia, Goiânia, 2017.

MENDES, M. F.; NEVES, S. M. A. S.; MACHADO, T. S. The Food Acquisition Program as an inducer of food sovereignty. Mercator, Fortaleza, v. 18, e18024, p. 1-15, 2019.

MONTEIRO, D. C. B.; PIRES, C. R. F. Avaliação da estabilidade físico-química de geleias de murici armazenadas sob diferentes condições de temperatura e luminosidade. Revista Desafios, Palmas, v. 03, n. especial, p. 87-98, 2016. 
MOURA, O. O.; SANTOS, A. C. P.; ARAÚJO, S. R.; MENDES, M. F.

O Mercado Municipal de Araguaína/TO como propulsor de alimentos do Cerrado

OLIVEIRA, A. G.; COSTA, M. C. D.; ROCHA, S. M. B. M. Benefícios funcionais do açaí na prevenção das doenças cardiovasculares. Journal of Amazon Health Science, v. 1, n.1, p.1$10,2015$.

PUHL, V. J. De uma agricultura sustentada à sustentável. Caderno Mato Grosso

Sustentável e Democrático. Cuiabá: Formad, 2006. p. 71-83.

RAFFESTIN, Claude. Por uma Geografia do poder. SP: Ática, 1993.

REIS, A. F.; SCHMIELE, M. Características e potencialidades dos frutos do cerrado na indústria de alimentos. Brazilian Journal of Food Technology, Campinas, v. 22, p. 1-12, 2019.

RIBEIRO, C. L.; PEREIRA, R. J.; PIRES, C. R. F.; LACERDA, G. E.; NASCIMENTO, G. N. L. Composição centesimal e aspectos físico-químicos dos frutos da bacaba (Oenocarpus distichus Mart.). Revista Cereus, Gurupi, v. 9, n. 3, p. 153-170, 2017.

RODRIGUES, E. T. Frutas do cerrado: a influência do cerrado na diversificação da gastronomia. 2004. 88 f. Monografia (Pós-graduação em Gastronomia e Segurança Alimentar), Universidade de Brasília, Brasília/DF, 2004.

SILVA, R. A. Desigualdades socioespaciais na cidade média de Araguaína-TO. 2016. 181 f. Tese (Doutorado em Geografia) - Universidade Estadual do Ceará, Centro de Ciências e Tecnologia, Fortaleza, 2016.

SOUZA, L. B. Implicações climática de um modelo neodesenvolvimentista: impactos, riscos e injustiças no estado do Tocantins, Brasil. Revista Brasileira de Climatologia, Curitiba, v. 19, n. 12, p. 129-145, 2016.

TUAN, YI-FU. Espaço e Lugar: a perspectiva da experiência. São Paulo: DIFEL, 1983.

ZUNINGA, A.; COQUEIRO, K. T. O.; SIQUEIRA, M. A. S. Capacidade antioxidante de frutos nativos do cerrado (Hancornia speciosa, Campomanesi axanthocarpa, Eugenia dysenterica) uma breve revisão. Revista Desafios, Palmas, v. 5, n. 1, p. 128-134, 2018. 
Osmar Oliveira de Moura - Possuiu Graduação em Geografia pela Universidade Federal do Tocantins (UFT). Atuou como bolsista CAPES no Programa Institucional de Bolsa de Iniciação à Docência (PIBID). Atualmente é Membro do Grupo de estudos "Educação para e no século XXI: diálogos interdisciplinares, escritas e eventos acadêmicos" e Grupo de Estudos Agrários e Direitos Humanos (GEADH/UFT).

Ana Caroline Pereira dos Santos - Possuiu Graduação em Geografia pela Universidade Federal do Tocantins (UFT). Bolsista do CNPq com o projeto de pesquisa intitulado "Dinâmica da Paisagem da microrregião geográfica de Araguaína/TO: subsídios para o planejamento e conservação ambiental" e integrante do grupo de pesquisa Análise da paisagem, conservação da biodiversidade e agroecologia na Amazônia Legal (GeoPaisagem).

Silvania Reis de Araújo - Graduanda em Geografia pela Universidade Federal do Tocantins (UFT).

Maurício Ferreira Mendes - Possuiu Graduação em Biologia e Geografia pela Universidade do Estado do Mato Grosso (UNEMAT), Mestrado em Ambiente e Sistemas de Produção Agrícola pela Universidade do Estado do Mato Grosso (UNEMAT) e Doutorado em Geografia pela Universidade Federal de Goiás (UFG). É professor do curso de Geografia da Universidade Federal do Tocantins (UFT), Câmpus Araguaína, e colaborador do programa de mestrado em Demandas Populares e Dinâmicas Regionais (PPGDire). Líder do grupo de pesquisa Análise da paisagem, conservação da biodiversidade e agroecologia na Amazônia Legal (GeoPaisagem).

Artigo recebido em: 11 de fevereiro de 2020.

Artigo aceito em: 07 de abril de 2020.

Artigo publicado em: 08 de abril de 2020. 